\title{
How developing countries should choose their financial regulatory framework? Empirical Analysis Based on Data from 62 Countries
}

\author{
Peng Zhong ${ }^{1}$, Tao $\mathrm{Wu}^{2}{ }^{2}$, Shuaixin Guo ${ }^{3}$ \\ ${ }^{1}$ School of Economics, Sichuan University, Chengdu city, Sichuan,610065, China. \\ ${ }^{2}$ School of Finance, Chongqing Technology and Business University, Chongqing, 400067, China. \\ ${ }^{3}$ Henan Academy of Macroeconomic Research, Zhengzhou city, Henan, 450003, China.
}

\begin{abstract}
This paper adopts the orderly logit model which has achieved good results in the research of financial supervision organization structure in recent years, selects 62 representative countries as samples, estimates and analyzes the factors that affect the financial supervision organization structure change, and carries on the empirical test to the constructed model, thus provides the reference basis for developing countries to select their own financial supervision organization structure.
\end{abstract}

\section{Introduction}

Since the 1990s, the international community and the financial community have carried out a series of studies on the organizational structure of financial supervision. In the early stage, we mainly used the cost-benefit analysis method to calculate the net income corresponding to different organizational structures of financial supervision. Since 2007, taking the research and exploration Masciandaro (2007) by foreign scholars as the main representative [1], the research on the organizational structure of financial supervision has been deepened into an empirical model. and its method is roughly to first identify the influencing factors, such as the financial regulatory system, the degree of financial development, the degree logit internationalization, and so on, and carry out an orderly model analysis of these factors in order to achieve the purpose of quantitative analysis of them.

And the biggest advantage of the ordered logit model is also the biggest difficulty lies in the determination of the model factors. Therefore, the basis of model construction lies in the rational analysis and establishment of the key areas of influencing factors. Specific to the optimization of financial regulatory organizations, although different countries have different regulatory structures, but generally by a country's economic, institutional, legal and other factors. Therefore, the identification of factors affecting the financial regulatory framework can be roughly from four aspects: financial regulatory system, financial development level, national political governance, economic and financial law.

Based on the analysis of the four aspects of financial supervision system, financial development level, national political governance, economic and financial law, we can further model the factors that affect the financial supervision concentration (FAC) index. That is to say, the financial supervision concentration degree (FAC) index is taken as the dependent variable, and the relevant influencing factors in the four major influencing factor areas are taken as independent variables, and the following eight variable indicators are selected: CBFA 、GDP 、MCAP 、mix 、cb_mpi 、 wgi 、 con 、 osp.: These eight indicators cover the core content of the four major impact factor areas and can form a more objective and scientific financial regulatory concentration measurement model. We adopts this model which has achieved good results in the research of financial supervision organization structure in recent years, selects 62 representative countries as samples, thus provides the reference basis for developing countries to select their own financial supervision organization structure.

\section{Variables, data and models}

\section{A. Assignment of variables}

Earlier, we selected eight variables, such as CBFA 、GDP 、 MCAP 、 mix 、 cb mpi 、 wgi 、 con 、osp, to analyze the concentration of financial regulation. These indicators are defined and assigned as follows:

\section{1) FAC indicators}

FAC indicator is a country's financial supervision concentration index. because the concentration of financial supervision is qualitative data, in order to facilitate the transformation of qualitative data into quantitative indicators, we use the "assigned value" method to represent each authoritative type. The value range of the index is [0:7], and the value is integer data, where the higher the value, the higher the value represents the degree of concentration of financial supervision in the country. Specifically defined as: $F A C=7$, on behalf of the insurance, banking and securities markets, there is a single regulatory body that supervises all financial institutions (total number of regulators $=1$ ); $\mathrm{FAC}=5$ on behalf of banks and securities markets there is a regulatory body (total number of regulators $=2$ ); $\mathrm{FAC}=3$ on behalf of insurance and securities or insurance and banks there is a regulatory body (total number of regulators $=2$ ); and $F A C=1$ on behalf of insurance, securities, and banking markets there is a regulatory body (total number of regulators $=3$ ).

However, these "numerical assignments" do not fully measure some of the special characteristics of financial regulation. For example, an industry is often regulated by multiple authorities at the same time. Therefore, we use the

\footnotetext{
*Corresponding author's e-mail: WUTAO@ctbu.edu.cn
} 
following principles to amend these special cases: when there are two or more regulators in one department, if one of the regulators is also responsible for the supervision of at least one other department, the FAC indicator is added 1 on the basis of the original set value; if there are two or more regulators in one department, if these regulators do not regulate the other department, the FAC indicator is subtracted from the original set value by $1[2]$.

\section{2) $C B F A$ Indicators}

CBFA indicators indicate the extent to which central banks are involved in financial regulation. To describe the status of the central bank, We introduce a measure of how much central banks are involved in financial regulation, i.e. the extent to which the central bank participates in financial regulation (CBFA). The index ranges from [0:4], And the higher the CBFA, The greater the scope of central bank supervision, The more regulatory authorities, the deeper the degree of participation in financial regulation. $\mathrm{CBFA}=1$ represents the Central Bank and is not responsible for the regulation of any financial sector; $\mathrm{CBFA}=2$ On behalf of the Central Bank, the central bank is responsible for the supervision of only one department (one of the three banks or securities or insurance); $\mathrm{CBFA}=3$ is responsible for the supervision of any two departments on behalf of the Central Bank (bank or securities or insurance bis); $\mathrm{CBFA}=4$ is responsible for the supervision (banking and securities and insurance) of all departments on behalf of the central bank[3].

Masciandaro is the pioneer representative figure in the field of quantitative research on financial supervision. We draw on Masciandaro (2018) latest paper data and processing ideas to sort out the latest situation of financial regulatory agencies in various countries. The details are shown in Table 1 .

Table 1 Financial regulation in 105 major countries of the world

\begin{tabular}{|c|c|c|c|c|c|c|c|c|c|c|c|}
\hline Country & Bank & Insurance & Securities & FAC & CBFA & Country & Bank & Insurance & Securities & FAC & CBFA \\
\hline Afghanistan & $\mathrm{CB}$ & I & $\mathrm{CB}$ & 3 & 3 & Kuwait & $\mathrm{CB}$ & G & s & 1 & 2 \\
\hline Albania & CB & IS & IS & 3 & 2 & Latvia & $\mathrm{U}$ & U & $\mathrm{U}$ & 7 & 1 \\
\hline Algeria & $\mathrm{CB}$ & I & S & 1 & 2 & Lebanon & $\mathrm{CB}, \mathrm{B}$ & I & s & 0 & 2 \\
\hline Argentina & $\mathrm{CB}$ & I & s & 1 & 2 & Lithuania & $\mathrm{CB}$ & $\mathrm{CB}$ & $\mathrm{CB}$ & 7 & 4 \\
\hline Armenia & $\mathrm{CB}$ & $\mathrm{CB}$ & $\mathrm{CB}$ & 7 & 4 & Luxembourg & BS & I & BS & 3 & 1 \\
\hline Australia & BI & BI & $\mathrm{s}$ & 5 & 1 & Macedonia & $\mathrm{CB}$ & I & $\mathrm{s}$ & 1 & 2 \\
\hline Austria & $\mathrm{CB}, \mathrm{U}$ & $\mathrm{U}$ & U & 6 & 2 & Malaysia & $\mathrm{CB}, \mathrm{G}$ & $\mathrm{CB}, \mathrm{G}$ & s & 5 & 3 \\
\hline Azerbaijan & $\mathrm{CB}$ & I & s & 1 & 2 & Malta & $\mathrm{U}$ & U & $\mathrm{u}$ & 7 & 1 \\
\hline Bahrain & CB & CB & $\mathrm{CB}$ & 7 & 4 & Mauritius & СB & IS & IS & 3 & 2 \\
\hline Bangladesh & $\mathrm{CB}$ & I & s & 1 & 2 & Mexico & BS & I & BS & 3 & 1 \\
\hline Barbados & $\mathrm{CB}$ & IS & IS & 3 & 2 & Moldova & $\mathrm{CB}$ & IS & IS & 3 & 2 \\
\hline Belarus & CB & G & G & 3 & 2 & Mongolia & CB & IS & IS & 3 & 2 \\
\hline Belgium & $\mathrm{CB}$ & $\mathrm{CB}$ & $\mathrm{CB}$ & 7 & 4 & Republic of Montenegro & $\mathrm{CB}$ & I & s & 1 & 2 \\
\hline Bermuda & $\mathrm{CB}$ & $\mathrm{CB}$ & $\mathrm{CB}$ & 7 & 4 & Morocco & $\mathrm{CB}$ & G & s & 1 & 2 \\
\hline Bolivia & B & IS & IS & 3 & 1 & Namibia & $\mathrm{CB}$ & IS & IS & 3 & 2 \\
\hline \begin{tabular}{|l} 
Bosnia \\
Bosnia and Herzegovina
\end{tabular} & \begin{tabular}{|l|}
$\mathrm{CB}$, \\
$\mathrm{B}^{* *}$
\end{tabular} & I & $\mathrm{s}$ & 0 & 2 & Netherlands & $\mathrm{CB}$ & $\mathrm{CB}$ & $\mathrm{CB}$ & 7 & 4 \\
\hline Botswana & $\mathrm{CB}$ & G & G & 3 & 2 & New Zealand & $\mathrm{CB}$ & $\mathrm{CB}$ & s & 5 & 3 \\
\hline Brazil & $\mathrm{CB}$ & I & $\mathrm{s}$ & 1 & 2 & Nicaragua & $\mathrm{U}$ & $\mathrm{u}$ & $\mathrm{u}$ & 7 & 1 \\
\hline Bulgaria & $\mathrm{CB}$ & IS & IS & 3 & 2 & Norway & $\mathrm{u}$ & $\mathrm{U}$ & $\mathrm{U}$ & 7 & 1 \\
\hline Canada & BI & BI & $\mathrm{S}^{* *}$ & 5 & 1 & Pakistan & $\mathrm{CB}$ & IS & IS & 3 & 2 \\
\hline Chile & $\mathrm{CB}, \mathrm{U}$ & $\mathrm{U}$ & u & 6 & 2 & Panama & B & I & s & 1 & 1 \\
\hline China & B & I & s & 1 & 1 & Peru & $\mathrm{U}$ & U & $\mathrm{u}$ & 7 & 1 \\
\hline Colombia & $\mathrm{U}$ & $\mathrm{U}$ & U & 7 & 1 & Philippines & $\mathrm{CB}$ & I & s & 1 & 2 \\
\hline Costa Rica & B & I & s & 1 & 1 & Poland & $\mathrm{U}$ & U & u & 7 & 1 \\
\hline Croatia & $\mathrm{CB}$ & IS & IS & 3 & 2 & Portugal & $\mathrm{CB}$ & I & s & 1 & 2 \\
\hline Cyprus & CB & I & $\mathrm{s}$ & 1 & 2 & Qatar & CB & $\mathrm{CB}$ & $\mathrm{CB}$ & 7 & 4 \\
\hline Czech Republic & $\mathrm{CB}$ & CB & $\mathrm{CB}$ & 7 & 4 & Republic of Korea & $\mathrm{CB}$ & $\mathrm{CB}$ & $\mathrm{s}$ & 5 & 3 \\
\hline Denmark & $\mathrm{U}$ & $\mathrm{U}$ & u & 7 & 1 & Romania & $\mathrm{CB}$ & IS & IS & 3 & 2 \\
\hline Dominican Republic & B & I & $\mathrm{s}$ & 1 & 1 & Russia & $\mathrm{CB}$ & CB & $\mathrm{CB}$ & 7 & 4 \\
\hline Ecuador & BI & BI & s & 5 & 1 & Saudi Arabia & $\mathrm{CB}$ & $\mathrm{CB}$ & s & 5 & 3 \\
\hline Egypt & $\mathrm{CB}$ & IS & IS & 3 & 2 & Singapore & $\mathrm{CB}$ & $\mathrm{CB}$ & СВ & 7 & 4 \\
\hline El Salvador & $\mathrm{U}$ & $\mathrm{U}$ & u & 7 & 1 & Slovakia & $\mathrm{CB}$ & $\mathrm{CB}$ & $\mathrm{CB}$ & 7 & 4 \\
\hline Estonia & U & U & u & 7 & 1 & Slovenia & $\mathrm{CB}$ & I & s & 1 & 2 \\
\hline Finland & $\mathrm{U}$ & $\mathrm{U}$ & u & 7 & 1 & South Africa & $\mathrm{CB}$ & IS & IS & 3 & 2 \\
\hline France & CB & $\mathrm{CB}$ & $\mathrm{s}$ & 5 & 3 & South Korea & $\mathrm{U}$ & $\mathrm{u}$ & $\mathrm{U}$ & 7 & 1 \\
\hline Georgia & $\mathrm{CB}$ & I & $\mathrm{CB}$ & 3 & 3 & Spain & $\mathrm{CB}$ & I & s & 1 & 2 \\
\hline Germany & $\mathrm{CB}, \mathrm{U}$ & $\mathrm{U}$ & u & 6 & 2 & Sri Lanka & СВ & I & s & 1 & 2 \\
\hline Greece & $\mathrm{CB}$ & $\mathrm{CB}$ & S & 5 & 3 & Sweden & U & U & $\mathrm{U}$ & 7 & 1 \\
\hline Guatemala & BI & BI & s & 5 & 1 & Switzerland & $\mathrm{U}$ & $\mathrm{u}$ & $\mathrm{u}$ & 7 & 1 \\
\hline Hong Kong Focus & CB & I & $\mathrm{s}$ & 1 & 2 & Thailand & $\mathrm{CB}$ & I & s & 1 & 2 \\
\hline Hungary & $\mathrm{CB}$ & $\mathrm{CB}$ & Св & 7 & 4 & Bahamas & $\mathrm{CB}$ & G & s & 1 & 2 \\
\hline Iceland & U & $\mathrm{U}$ & u & 7 & 1 & Trinidad Island & $\mathrm{CB}$ & $\mathrm{CB}$ & s & 5 & 3 \\
\hline
\end{tabular}




\begin{tabular}{|c|c|c|c|c|c|c|c|c|c|c|c|}
\hline India & CB & I & S & 1 & 2 & Tunisia & $\mathrm{CB}$ & I & $\mathrm{s}$ & 1 & 2 \\
\hline Indonesia & U & $\mathrm{U}$ & U & 7 & 1 & Turkey & B & I & s & 1 & 1 \\
\hline Iran & CB & I & S & 1 & 2 & Ukraine & $\mathrm{CB}$ & IS & IS & 3 & 2 \\
\hline Ireland & CB & $\mathrm{CB}$ & $\mathrm{CB}$ & 7 & 4 & \begin{tabular}{|l|} 
Arab League \\
United Emirates
\end{tabular} & $\mathrm{CB}$ & $\mathrm{CB}$ & s & 5 & 3 \\
\hline Israel & $\mathrm{CB}$ & G & s & 1 & 2 & Britain & $\mathrm{CB}$ & $\mathrm{CB}$ & $\mathrm{CB}$ & 7 & 4 \\
\hline Italy & $\mathrm{CB}$ & $\mathrm{CB}$ & S & 5 & 3 & United States of America & $\mathrm{CB}, \mathrm{B}^{* *}$ & $\mathrm{CB}, \mathrm{I} * *$ & $\mathrm{~S}^{* *}$ & 2 & 3 \\
\hline Jamaica & $\mathrm{CB}$ & IS & IS & 3 & 2 & Uruguay & $\mathrm{CB}$ & $\mathrm{CB}$ & $\mathrm{CB}$ & 7 & 4 \\
\hline Japan & $\mathrm{U}$ & $\mathrm{U}$ & U & 7 & 1 & Venezuela & B & I & s & 1 & 1 \\
\hline Jordan & $\mathrm{CB}$ & G & I & 1 & 2 & Zimbabwe & $\mathrm{CB}$ & I & $\mathrm{s}$ & 1 & 2 \\
\hline Kazakhstan & $\mathrm{CB}$ & $\mathrm{CB}$ & $\mathrm{CB}$ & 7 & 4 & & & & & & \\
\hline Kosovo & CB & $\mathrm{CB}$ & $\mathrm{CB}$ & 7 & 4 & & & & & & \\
\hline
\end{tabular}

Data source: Donato Masciandaro, Davide Romelli.Central bankers as supervisors: Do crises matter.European Journal of Political Economy.2018(52):120-140(note: data deadline 2013)

The letter B indicates the sector that supervises the banking sector only; the letter $\mathrm{S}$ the sector that supervises the securities industry only; the letter I the sector that supervises the insurance industry only; the $U$ that supervises the three industries uniformly; the BS that supervises the banking and securities industries; the BI that supervises the banking and insurance industries; the $\mathrm{CB}$ that the central bank; the SI that supervises the securities and insurance industries; and the ** that states and regions.

Although there are 105 countries in the table, due to the lack of data in other variables, we finally selected 62 of them as samples to study, the sample size meets the requirements of data analysis, and has a high credibility.

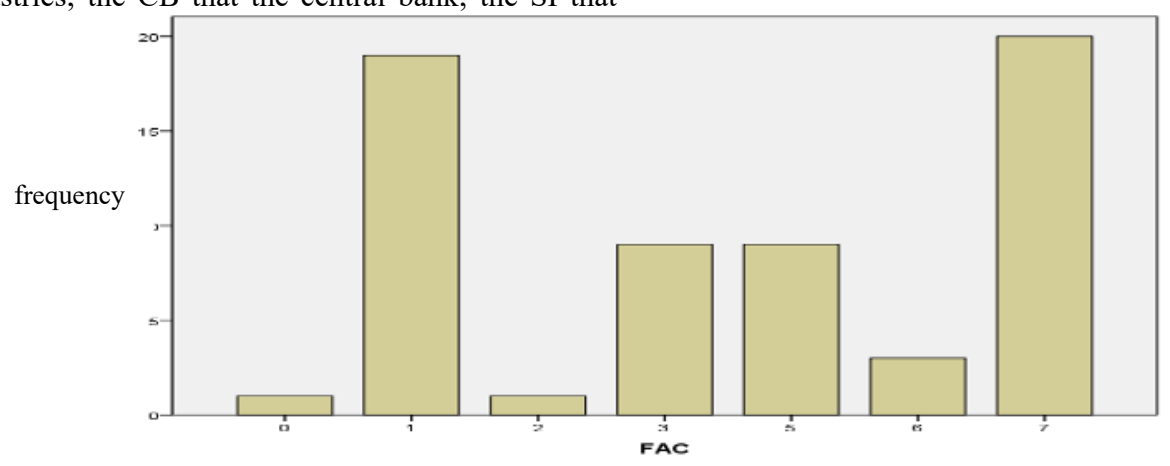

Figure 1. FAC Classification

Figure 1 shows that in the 62 sample countries, there is a polarization of financial regulation: in 20 countries, the FAC indicator is equal to 1 or 0 , that is, the concentration of financial regulation in these countries is very scattered, at the same time, $\mathrm{FAC}=7$ in 20 countries, that is, there is only one regulator in the three industries of banking, securities and insurance, and the concentration of financial regulation is very high, which shows that for the organizational structure of financial regulation, each country has its own choice according to its own national conditions.

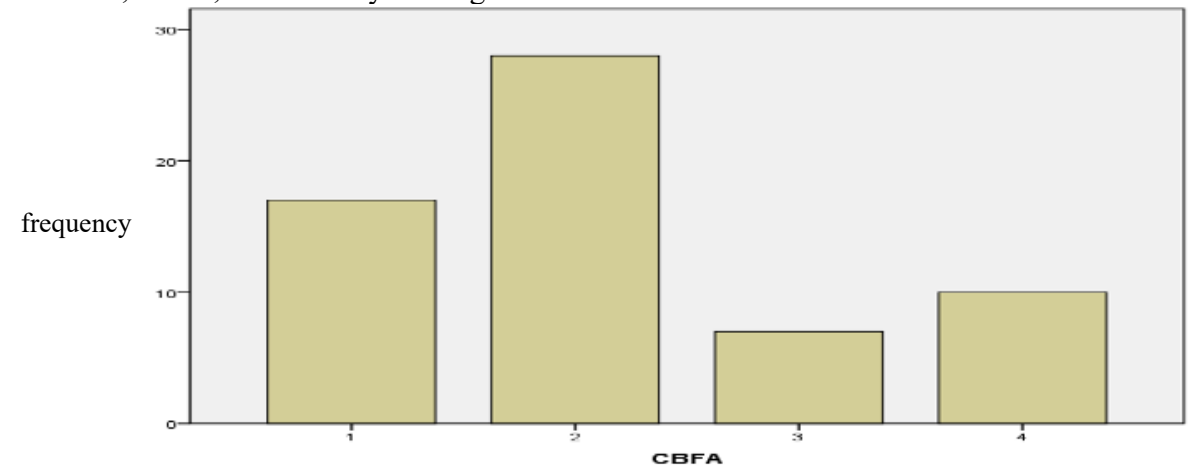

Figure 2 CBFA Classification

As can be seen from figure 2, the degree of participation of the central bank in financial supervision is relatively shallow in most countries, with the central banks in 17 countries not participating in financial supervision, and the central banks in 28 countries only regulate one sector of banks, securities and insurance. Only 10 countries' central banks regulate all three industries, and participate in financial regulation to a higher extent.

\section{3) GDP Indicators}

GDP, To measure the impact of the scale of economic development on the organizational structure of financial regulation, Here we refer to Masciandaro (2008 、 2009) treatment, Measuring the impact on the FAC of 2013 by averaging GDP data for 2003,2005,2007,2009 and 2015, For the purpose of reducing the dimensionality impact between GDP and other indicators, And we log the GDP, the processed GDP variables are represented by LnGDP. Data from World Bank World Development Indicators, Of which, Country GDP 
totals are calculated in United States dollars for 2010.1

\section{4) Mcap Indicators}

Mcap is the degree of capitalization of financial market, which is used to measure the degree of capitalization of domestic financial market. the formula is the ratio of market value to GDP of stock market. referring to the treatment of Masciandaro (2009), we take the mean value of data from $2003,2005,2007,2009,2015$ into the model, and the data are derived from the world development index of the world bank.(2)

\section{5) Mix Indicator}

Mix indicator is the financial mix index. The financial mix index ranges from 0 to 4 , The larger the index, That suggests that the country's financial sector is more cross-cutting. This indicator can be found in World Bank survey data, The surveys were conducted in 1999,2003,2007 and 2011, respectively. Four times. On the content of the survey indicators, We can be scored in the range 1-4(rounded), The higher the value, the greater the limit, The lower the value, the smaller the limit. Specifically, At 1, Which means not limited, The bank can do this directly, and is not subject to specialized key supervision; At 2, Which means moderate, The bank may conduct the financial business within its supervision, But part of the financial business may need to be done indirectly; At 3, That means limits, Banks and their subsidiary financial institutions may participate in part of the financial business, but subject to more stringent regulation; At 4, Which means forbidden, Banks and their subsidiaries are not allowed to participate in related restricted financial operations. In terms of index processing, These three indicators can be weighted average, And give the same weight, Used to represent the degree of mixing. In the processing of related data, Using data from three surveys conducted by the World Bank in 2003,2007 and 2011, and then averaged treatment. Data source: World Bank surveys on bank regulation (3).

6) $C B \_$mpi Indicators

CB_mpi indicator is the central bank's macroprudential policy regulatory index. The index reflects the extent to which central banks regulate macroprudential policies. The 2013 International Monetary Fund survey sought to examine 12 macroprudential instruments available to central banks as of 2013, including debt-to-income ratio, leverage ratio, loan-to-value ratio caps, which were treated with macroprudential indicators (MPI) and central bank macroprudential policy regulatory indicators (CB_mpi). Eugenio Cerutti (2017). of data sources(4)(5)

\section{7) WGI Indicators}

WGI indicator (world governance index) is a country's governance level indicator. The range of this indicator is $(-2.5: 2.5)$, and the larger the value, the higher the level of governance in the country. The index was first published in the

\footnotetext{
(1) Source: World Bank. URL: http://databank.shihang.org/data/report s.aspx? of the World Development Index source=world-develop ment-indicators \#selectedDimension DBList.

${ }^{2}$ Source: World Bank. URL: . of the World Development Indexhtt p://databank.shihang.org/data/reports.aspx? source=world-developm ent-indicators \#selectedDimension_DBList

3) Source: World Bank surveys on bank regulation Data Download link: http://faculty.haas.berkeley.edu/ross_levine/Papers/Copy $\% 20$ of\%20BCL Sup Reg Data 13JAN2013.xls, Reference: James R. Barth,Gerard Caprio,Jr.,Ross Levine.BANK REGULATION AND SUPERVISION IN 180COUNTRIES FROM 1999TO 2011.201 3.1.URL: http://www.nber.org/papers/w18733.:

${ }^{4}$ Donato Masciandaro,Davide Romelli .Central bankers as superviso rs: Do crises matter? European Journal of Political Economy.20 18(52): 120-140.

55 Eugenio Cerutti,Stijn Claessens and Luc Laeven.The use and eff ectiveness of macroprudential policies: New evidence.Journal of Financial Stability.2017(28): 203-224 data download: http://www. imf.org/external/pubs/ft/wp/2015/Data/wp1561.zip.
}

world at the end of the 20th century by kauffman, the founder of the index, which provides a new way to combine quantitative comparable indices with multi-tier governance measurements for financial regulation research. The WGI includes six main indicators: expression and accountability (VA), political stability and violence-free (pv), government effectiveness (GE), regulatory quality (RQ), rule of law (RL), corruption and control (CC).WGI indicators have good design planning and continuous robustness, so they have attracted wide attention worldwide and are widely used as explanatory variables to analyze the development of world financial regulation.Besides using WGI data by averaging six indicators to form comprehensive management level indicators, we averaged the data for 2003,2005,2007,2009,2011 and incorporated the final WGI indicators into our research model. data from the world governance index.(6)

\section{8) CON Indicators}

A CON indicator, namely, bank concentration, is used to characterize the degree of centralization of a country's previous major banking operations over the entire banking system. A more general approach is to calculate the sum of the deposits of the country's five largest and most influential banks, compared with the sum of the deposits of the national banks, which is the ratio of bank concentration. Generally speaking, the higher the concentration of a country's banks, the stronger the strength of financial interest groups, and the more motivated it is to take various means to influence the financial supervision of the government, the more unfavorable it is to the development [4] of finance. In data processing, the last three surveys ,2003,2007 and 2011, were used to average data. Data from: World Bank surveys on bank regulation.

\section{9) OSP Indicators}

OSP indicator is the regulatory authority of the regulatory authority. It's mainly used to describe problems in banking, Whether the regulatory authorities have the right to take action to correct these problems, The range is [0:14], The higher the value, indicating that the greater the regulatory power of the government. During data processing, Found that Ecuador, Ireland, Japan, Sweden and Ukraine are missing in this indicator, For the purpose of keeping the sample, For these five missing values, We fill it with the mean of the variable ,11, so as to minimize the impact of missing values on the model. In the processing of data, We take the average of the data from three surveys in 2003,2007 and 2011 into the model. Data from World Bank surveys on bank regulation. source

10) $\boldsymbol{\varepsilon}_{\boldsymbol{i}}$ : The random error term, assuming a mean of 0 , is a standard normal distribution with a standard deviation of 1 . B. Statistical description of variables

The basic statistics of 1 dependent variable and 8 independent variables are described using statistical software SPSS22 according to the constructed ordered logit model. The specific analysis results are shown in Table 2.

\footnotetext{
World Governance Index: home. URL: http://info.worldbank.org/ governance/wgi/index.aspx \#
} 
Table 2. Basic Statistics Description Analysis Based on Software SPSS22

\begin{tabular}{|c|c|c|c|c|c|c|c|c|c|}
\hline & Figures & $\begin{array}{c}\text { Minimum } \\
(\mathrm{M})\end{array}$ & $\begin{array}{c}\text { Maximum } \\
(\mathrm{X})\end{array}$ & Average (E) & $\begin{array}{c}\text { Standard } \\
\text { deviation }\end{array}$ & \multicolumn{3}{|c|}{ Deviation } & \multicolumn{2}{|c|}{ kurtosis } \\
\cline { 2 - 10 } & Statistics & Statistics & Statistics & Statistics & Statistics & Statistics & $\begin{array}{c}\text { Standard } \\
\text { error }\end{array}$ & $\begin{array}{c}\text { Statistics } \\
\text { Standard error }\end{array}$ \\
\hline FAC & 62 & 0 & 7 & 4.05 & 2.563 & -.080 & .304 & -1.685 & .599 \\
\hline CBFA & 62 & 1 & 4 & 2.16 & 1.011 & .648 & .304 & -.582 & .599 \\
\hline MCAP & 62 & 4.08 & 852.77 & 75.2747 & 112.13877 & 5.718 & .304 & 38.826 & .599 \\
\hline MIX & 62 & 1.00 & 8.00 & 2.4629 & 1.21352 & 3.078 & .304 & 12.762 & .599 \\
\hline CB_mpi & 62 & .00 & 1.00 & .4861 & .43007 & .099 & .304 & -1.718 & .599 \\
\hline wgi & 62 & -1.04 & 1.88 & .5421 & .83179 & -.081 & .304 & -1.329 & .599 \\
\hline lngdp & 62 & 22.83 & 30.31 & 26.2734 & 1.61324 & .103 & .304 & -.242 & .599 \\
\hline con & 62 & 27.15 & 96.53 & 66.1039 & 16.74582 & -.125 & .304 & -.582 & .599 \\
\hline osp & 62 & 7.50 & 14.00 & 11.0256 & 1.78643 & -.020 & .304 & -1.175 & .599 \\
\hline N & 62 & & & & & & & \\
\hline
\end{tabular}

It can be seen from Table 6-2 that the mean values of each explanatory variable are located in a reasonable interval, which shows that the model is reasonable for the statistical description of each variable, which can also verify to a certain extent that the factor hypothesis proposed by us is in line with the basic present situation of the financial regulatory organization system.

By comparing the mean values of explanatory variables horizontally, As you can see, MCAP mean the highest, 75.2747, And this indicates that the degree of capitalization of financial markets in the orderly logit model has the most significant effect on the concentration of financial supervision, This also reflects the importance of financial market capitalization to financial regulation; $\mathrm{CB}$ mpi mean the lowest, 0.4861 , And this indicates that the central bank's macroprudential index in the orderly logit model has the least significant effect on the concentration of financial supervision among the eight independent variables, Reflecting the central bank's implementation of macro-financial policy instruments are currently relatively small impact on the entire financial regulatory system. Similar to these two indicators: the concentration of banks $(\mathrm{CON})$ has a relatively large impact on the concentration of financial regulation, Mean 66.1039, As a result, the degree of bank concentration in the orderly logit model has a great influence on the financial supervision system. have a significant positive impact on financial regulatory organizations; wgi mean is only higher than CB_mpi, 0.5421 , indicating that the comprehensive management level of a country in the orderly logit model has a relatively limited impact on the financial regulatory system, The level of governance does not significantly affect the operation of the financial regulatory organization system.

The following models are then developed:

\section{$\mathrm{FAC}=\beta_{0} \beta_{1} c b f a_{+} \beta_{2 \operatorname{lnGDP}} \beta_{3} M \operatorname{cap} \beta_{4} m i x_{+} \beta_{5 \mathrm{C}}$} $\mathrm{B}_{-} \mathrm{mpi}+\beta_{6 \mathrm{wgi}}+\beta_{7} \operatorname{con}+\beta_{8 \mathrm{osp}} \varepsilon_{i}$

\section{Collinearity Test and Parallel Line Test}

\section{A. Collinearity test}

To detect whether there is multiple collinearity between variables, we use spss22 software to detect the data with multiple collinearity. the results are as follows:

Table 3. Results of multiple collinearity detection of explanatory variables based on spss 22 software

\begin{tabular}{|c|c|c|c|}
\hline \multirow{2}{*}{\multicolumn{2}{|c|}{ Model }} & \multicolumn{2}{|c|}{ collinear statistics } \\
\hline & & Admissibility & VIF \\
\hline \multirow{8}{*}{1} & CBFA & .833 & 1.200 \\
\hline & MCAP & .833 & 1.201 \\
\hline & MIX & .896 & 1.116 \\
\hline & CB_mpi & .694 & 1.441 \\
\hline & wgi & .641 & 1.559 \\
\hline & lngdp & .767 & 1.304 \\
\hline & con & .783 & 1.277 \\
\hline & osp & .872 & 1.147 \\
\hline \multicolumn{4}{|c|}{ a. dependent variable: FAC } \\
\hline
\end{tabular}

From Table 3, it can be seen that the variance expansion factor (VIF) of each scalar is located in the 1-2 interval, which is far less than the upper limit of 10 ; the tolerance of each variable is in the range of $0.64-0.90$, which is far greater than the lower limit of 0.1 tolerance. Considering the above numerical conditions of variance expansion factor (VIF) and tolerance, it can be concluded that there is no multiple collinearity between the explanatory variables.

\section{B. Parallel Line Detection}

Parallel line inspection results are shown in Table 6-3.

Table 4. Parallel Line Test Results

\begin{tabular}{|c|c|c|c|c|}
\hline Model & -2 Logarithmic likelihood & Chi Fang (i) & df & Significant \\
\hline $\begin{array}{c}\text { Original } \\
\text { assumptions }\end{array}$ & 167.504 & & & \\
\hline Conventional & $112.789^{\mathrm{b}}$ & $54.715^{\mathrm{c}}$ & 40 & .060 \\
\hline
\end{tabular}


Note: zero assumes that the specified position parameters (slope coefficients) are identical in each response category.

a. join function: Logit;

b. the logarithmic likelihood can not be further increased after the maximum number of steps.

c. calculation of chi-square statistics is based on the logarithmic likelihood value obtained by the last iteration of the generalized model; the validity of the test is uncertain.
As can be seen from Table 4 , the $\mathrm{p}$ value detected by parallel lines is 0.06 , which is greater than the significant level of 0.5 . hence, accepting the original assumption that the various regression equations are parallel to each other, an ordered logit model can be used.

\section{Evidence}

The ordered logit model is estimated using spss 22 software as shown in the following table:

Table 5. Model parameter estimates for ordered logit models

\begin{tabular}{|c|c|c|c|c|c|c|c|c|c|c|c|}
\hline & \multirow{2}{*}{$\begin{array}{l}\text { Estimate } \\
\text { (E) }\end{array}$} & \multirow{2}{*}{$\begin{array}{l}\text { Standard } \\
\text { error }\end{array}$} & \multirow{2}{*}{ Wald } & \multirow{2}{*}{ df } & \multirow{2}{*}{ Significant } & \multicolumn{2}{|c|}{\begin{tabular}{|ll}
$95 \%$ & confidence \\
interval & \\
\end{tabular}} & \multirow{2}{*}{$\begin{array}{l}\text { Estimates } \\
\text { of Ubisoft } \\
\text { (OR) }\end{array}$} & \multicolumn{2}{|c|}{\begin{tabular}{|ll}
$95 \%$ & confidence \\
interval & \\
\end{tabular}} \\
\hline & & & & & & & \begin{tabular}{|l|} 
Lower \\
limit
\end{tabular} & $\begin{array}{l}\text { Upper } \\
\text { limit }\end{array}$ & & $\begin{array}{l}\text { Lower } \\
\text { limit }\end{array}$ & $\begin{array}{l}\text { Upper } \\
\text { limit }\end{array}$ \\
\hline \multirow[t]{6}{*}{ Threshold } & $\begin{array}{l}{[\mathrm{FAC}} \\
=0]\end{array}$ & 3.773 & 5.843 & .417 & 1 & .518 & -7.680 & 15.225 & 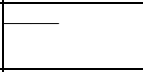 & & - \\
\hline & \begin{tabular}{|l|} 
[FAC \\
$=1]$
\end{tabular} & 7.600 & 5.863 & 1.680 & 1 & .195 & -3.892 & 19.091 & - & $\overline{-}$ & - \\
\hline & \begin{tabular}{|l|}
{$[$ FAC } \\
$=2]$ \\
\end{tabular} & 7.690 & 5.865 & 1.720 & 1 & .190 & -3.804 & 19.184 & - & - & ב \\
\hline & \begin{tabular}{|l|}
{$[$ FAC } \\
$=3]$
\end{tabular} & 8.505 & 5.880 & 2.092 & 1 & .148 & -3.019 & 20.030 & 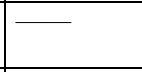 & $\bar{\square}$ & $\overline{ }$ \\
\hline & \begin{tabular}{|l|}
{$[$ FAC } \\
$=5]$
\end{tabular} & 9.370 & 5.898 & 2.523 & 1 & .112 & -2.191 & 20.930 & - & - & - \\
\hline & \begin{tabular}{|l|}
{$[$ FAC } \\
$=6]$
\end{tabular} & 9.663 & 5.905 & 2.678 & 1 & .102 & -1.910 & 21.236 & $\overline{-}$ & - & - \\
\hline \multirow[t]{8}{*}{ Position } & CBFA & -0.859 & 317 & 7.361 & 1 & .007 & 238 & 1.479 & 0.424 & 0.228 & 0.788 \\
\hline & \begin{tabular}{|l|}
$\mathrm{MCA}$ \\
$\mathrm{P}$ \\
\end{tabular} & 0.003 & .003 & 1.208 & 1 & .272 & $\mid-.008$ & .002 & 1.003 & 0.998 & 1.008 \\
\hline & \begin{tabular}{|l|} 
MIX \\
\end{tabular} & 0.017 & .205 & .006 & 1 & .936 & -.418 & .385 & 1.017 & 0.680 & 1.519 \\
\hline & $\begin{array}{l}\text { CB_m } \\
\text { pi }\end{array}$ & 1.366 & .730 & 3.504 & 1 & .061 & -2.797 & .064 & 3.921 & 0.938 & 16.394 \\
\hline & wgi & -0.903 & .368 & 6.038 & 1 & .014 & .183 & 1.624 & 0.405 & 0.197 & 0.833 \\
\hline & $\operatorname{lngdp}$ & -0.178 & .173 & 1.051 & 1 & .305 & -.162 & .517 & 0.837 & 0.596 & 1.176 \\
\hline & con & -0.024 & .017 & 1.885 & 1 & .170 &.- .010 & .057 & 0.977 & 0.944 & 1.010 \\
\hline & osp & \begin{tabular}{|l}
-0.092 \\
\end{tabular} & \begin{tabular}{|l|}
.148 \\
\end{tabular} & .386 & 1 & \begin{tabular}{|l|l|}
.534 \\
\end{tabular} & \begin{tabular}{|l|}
-.198 \\
\end{tabular} & .382 & 0.912 & 0.682 & 1.219 \\
\hline
\end{tabular}

Accordingly, according to the data analysis processing result, can obtain each variable coefficient then obtains the order logit model:

\section{FAC $=-0.859 \quad$ CBFAFAC $=0.003 \quad$ MCAPFAC $=0.017$ MIXFAC $=1.366$ \\ CB mpi-0.903WGI-0.178LNGDP-0.024CON-0.092OPS}

Table 5 data, the highest value FAC the explained variable means the unified regulatory organizational structure, and the lowest value means the multivariate regulatory organizational structure, but the effect of the change of the explanatory variable in the model on the highest or lowest value of the explained variable is more clear. That is, when the coefficient estimate of the explanatory variable is positive, it shows that the increase of the value of the explanatory variable will increase the probability of implementing the unified financial supervision organization structure; if the coefficient estimate of the explanatory variable is negative, it shows that the increase of the value of the explanatory variable will increase the probability of implementing the multivariate financial supervision organization structure in the country.

\section{Explanation of fruit}

According to the estimated results of the model in Table 5, according to the positive and negative coefficients of each index, it can be concluded that there is the following relationship between the influencing factors and the concentration of financial supervision:

First, the depth of financial supervision by the central bank is negatively related to the concentration (FAC) of financial supervision. The parameter estimate of CBFA index is -0.859 , which is negative and significant, which indicates that the depth of financial supervision by the central bank is negatively correlated with the concentration of financial supervision (FAC) This shows that the more central banks participate in financial supervision, the lower the degree of concentration of supervision in the country, the more inclined the central bank and other regulatory agencies to jointly supervise the financial industry, the more obvious the financial pluralistic regulatory organization system. On the other hand, the lower the participation of the central bank in financial supervision, the lower the position of the central bank in the whole financial supervision, the lower the concentration of financial supervision, the more inclined to implement unified supervision of financial affairs, the more obvious the system of financial unified supervision and organization.

Second, the degree of capitalization of financial markets is positively correlated with financial regulatory concentration (FAC).The parameter estimate of the MCAP index is 0.003 , which is positive, indicating that there is a positive correlation between the degree of capitalization of financial markets and the concentration of financial supervision (FAC). which indicates that the higher the ratio of stock market capital to GDP, the higher the concentration of financial supervision. In other words, the more developed a country's financial securities market and the higher the degree of capitalization of the financial market, the higher the concentration of financial supervision, the more the country tends to concentrate on a unified financial supervision system. 
Thirdly, there is a positive correlation between financial mixed degree and financial supervision concentration (FAC).MIX parameter estimate of the index is 0.017 , which is positive, indicating that there is a significant positive correlation between the degree of financial mixing and the concentration of financial supervision. This shows that the higher the degree of financial mixed operation, the more the financial supervision tends to be unified supervision, and the more the financial supervision system reflects the unified and centralized organizational structure. On the contrary, the lower the degree of financial mixed operation, the more financial supervision tends to multi-head regulatory system.

Fourth, there is a positive correlation between the macroprudential policy supervision index of the central bank and the concentration of financial supervision (FAC).The parameter estimate of the CM_MPI is 1.3666 , which is positive and significant, which indicates that there is obvious positive correlation between the macroprudential policy supervision index of the central bank and the concentration of financial supervision (FAC). That is to say, the higher the degree of prudence of the central bank using 12 macro-financial policy instruments, the higher the concentration of financial supervision in the country, and the stronger the organizational structure of financial supervision tends to unify centralized supervision. It can be seen that the prudential degree of the central bank in the use of financial policy instruments to regulate the financial market also has a significant impact on the operation of financial regulatory organizations, and has a positive correlation effect.

Fifth, there is a negative correlation between the level of comprehensive management of the country and the concentration of financial supervision (FAC).The parameter estimate of WGI is -0.903 , which is negative and significant, which indicates that there is obvious negative correlation between the level of comprehensive management and the concentration of financial supervision (FAC). This shows that the higher the level of comprehensive management in the country, the more the country's financial supervision tends to be unified and centralized management, and the regulatory system also shows a more obvious characteristics of centralized management. Usually, the higher the level of comprehensive management in a country, the better the efficiency of the government's management of all kinds of affairs, the more effective it is to the financial supervision, and the organizational system of financial supervision is gradually moving towards the characteristics of centralized and unified supervision, which is significantly related to the basic role of the government of the country.

Sixth, there is a negative correlation between the comprehensive strength of national economic development and the concentration of financial supervision (FAC).The parameter estimate of the LNGDP is -0.178 , which is negative, indicating that there is a negative correlation between the level of comprehensive strength of national economic development and the concentration of financial supervision (FAC). This shows that the higher the GDP of a country, the better the level of national economic development and the lower the concentration level of financial supervision. That is to say, the higher the GDP level of a country, the more financial supervision tends to separate supervision; conversely, the lower the GDP level of a country, the more financial supervision tends to concentrate on unified supervision. It should be noted that the relationship is not sufficiently significant, i.e. it is largely indicative of the tendency of the relationship. The United Kingdom and the United States, for example, have both high levels of economic development: the United Kingdom adopts a centralized and unified regulatory organization system, and the United States adopts a two-line and long regulatory organization system.

Seventh, there is a positive correlation between the concentration level of banks and the concentration of financial supervision (FAC). The parameter estimate of CON is 0.024 , which is positive, indicating that there is a positive correlation between the concentration level of bank finance and the concentration degree of financial supervision (FAC). This shows that a country's bank concentration can have a direct impact on the level of financial regulatory concentration: the higher the bank concentration, the higher the financial regulatory concentration; conversely, the lower the bank concentration, the lower the financial regulatory concentration. This result can be understood as the more traditional banking business is concentrated in several major banks, the more effective the regulatory organization level is through the supervision of these key banks and then the supervision of the whole financial market, to a certain extent can play the purpose of effective financial supervision by controlling the key few.

Eighth, the government's financial supervision power and financial supervision concentration (FAC) have a negative correlation. The parameter estimate of the OPS is -0.092 , which is negative, indicating that there is a certain degree of negative correlation between the government's financial supervision power and the financial supervision concentration (FAC). This shows that the greater the power of a government to financial supervision, the weaker the degree of concentration of financial supervision by the professional organization department of financial supervision; conversely, if a government does not have more authority or too narrow authority in financial supervision, the greater the degree of concentration of financial supervision by the professional organization department of financial supervision. Therefore, it can be considered that the excessive power of a government over financial supervision will dilute the role of financial regulatory professional organizations in the supervision of financial markets, and the lower the level of centralized supervision of financial regulatory organizations.

\section{Conclusions and Recommendations}

At present, the academic circles have not formed a unified understanding of what kind of financial supervision organization structure a country should adopt, Xie Ping, he Fan, Xiang Songzuo, Huang Haizhou and other scholars all said :" for a country, no plan is always optimal, no model is optimal for all countries around the world, there is no solution to solve all problems at the same time "[5].Because different financial supervision systems have different effects and welfare effects on countries in different stages of development, different domestic economic characteristics and different models of foreign economic relations. In other words, the structure of optimal financial supervision organization varies with the country and its development, and there is no one-size-fits-all "optimal financial supervision structure ". The choice of a country's financial supervision organization structure is actually the result of the combination of economic and financial structure, political and economic system, historical tradition, government and its ability, political restraint and legal environment. Studying the choice of the organizational structure of a country's financial regulation needs to incorporate these factors into a common analytical framework. On the surface, the choice of financial supervision organization structure is the result of decision-making authority's decision-making, but in fact, the net income and sustainability of financial supervision system determine that the choice of financial supervision organization structure has endogenous characteristics. More importantly, the choice of financial supervision organization structure is a dynamic transformation process with historical stages. Like other economic regulatory systems, institutional changes in financial regulation reflect changes in the preferences of policymakers and the public. Therefore, the choice of financial regulatory organizational structure is not once and for all, and there is no certain financial regulatory organizational structure suitable for all countries of 
the same period or all periods of the same country. In the long run, the financial regulatory organizational structure is an endogenous institutional arrangement, and countries will voluntarily or involuntarily change their financial regulatory organizational structure, and a specific financial regulatory organizational structure may only be suitable for a particular period and the needs of a particular country. Rather than looking for such an "optimal financial regulatory organizational structure ", we might as well analyze the applicability and sustainability of various financial regulatory organizational structures at different stages of development, describe the dynamic path of the evolution of financial regulatory organizational structure, reveal its endogeneity, and propose specific development directions for specific countries to choose financial regulatory organizational structure, which may be more meaningful to explain and solve the dilemma of financial regulatory organizational structure selection in developing countries.

\section{Acknowledgments}

This paper is funded by the Chinese National Funding of Social Science (the western program). Grant No. 16XGL005. The National Social Science Foundation is the main channel for China to support basic research in the field of scientific research.
It is oriented to the whole country and focuses on supporting researchers in Institutions of higher learning and scientific research institutions with good research conditions and research strength.

\section{References:}

[1] Donato Masciandaro. (2007)Determinants of Financial Supervision Regimes: Markets, Institutions, Politics, Law or Geography? [EB/OL].] http : $/ /$ papers.ssrn .com/sol3/papers.cfm? abstract_id $=957050$, 2007-01-03.

[2] Zhang Peng. Path Choice for Optimizing the Organizational Structure of Financial Supervision $[\mathrm{J}]$ Financial Forum ,2011(11):31-37.

[3] Wu Jinpeng, Zhang Yihao. Empirical Analysis on the Concentration of International Financial Supervision and its Enlightenment[J] Shanghai Finance ,2004(12):45-47.

[4] Jiang Chun, Xu Licheng. Financial Supervision and Financial Development: Theoretical Framework and Empirical Test [J] Financial Research .2005(4):79-88.

[5] Bu Yongxiang: Study on the Reform of Financial Supervision System [N].] Caixin .2016-2-29. 